GIL, Isabel; Loureiro, Ana Paula - "Os portugueses sabem bem desenrascar sem panicar."... Para lá da tarefa: implicar os estudantes na aprendizagem de línguas estrangeiras no ensino superior.

Porto: FLUP, 2019, pp. 149-166 DOI: https://doi.org/10.21747/9789898969217/paraa8

\title{
"Os portugueses sabem bem desenrascar sem panicar." (Alemão, B1) Perceções e construção da alteridade por aprendentes de PLE
}

\author{
Isabel Gil \\ Universidade de Coimbra / CELGA-ILTEC, Portugal \\ itmgil@sapo.pt \\ Ana Paula Loureiro \\ Universidade de Coimbra / CELGA-ILTEC, Portugal \\ olivelou@ci.uc.pt
}

\begin{abstract}
Resumo
O presente estudo tem como objetivo analisar manifestações da perceção e da construção da imagem do "outro" e da sua cultura (cultura alvo) em textos escritos por aprendentes de Português Língua Estrangeira / Língua Segunda, em contexto de imersão. Considerando o texto na sua dimensão temático-informativa, e partindo da unidade básica que o constitui (a frase), propomo-nos observar os processos de referenciação atualizados em torno de expressões nominais definidas do tipo "os portugueses", bem como as dimensões semântico-sintáticas que Ihes são atribuídas, quer ao nível frásico quer ao nível da organização da unidade discursivo-textual. Os dados para análise foram retirados do Corpus de Produções Escritas de Aprendentes de PL2 (PEAPL2), do CELGA/ILTEC.
\end{abstract}

Palavras-chave: PLE, perceção intercultural, emoção, referenciação, objetos de discurso

\begin{abstract}
This study analyses linguistic indications of the perception and the image-building process of the Other and their culture (target culture) in texts written by PFL learners, in an immersion context. Considering the thematic-informative textual dimension, taking into account that the sentence is the basic unit of a text, we focus on the processes of referenciation involved in nominal expressions like "os portugueses" (the Portuguese), as well on the semantic-syntactic roles attributed to those expressions, both at the sentence level and the discursive-textual level. The data used in this study were retrieved
\end{abstract}


GIL, Isabel; Loureiro, Ana Paula - "Os portugueses sabem bem desenrascar sem panicar."... Para lá da tarefa: implicar os estudantes na aprendizagem de línguas estrangeiras no ensino superior. Porto: FLUP, 2019, pp. 149-166 DOI: https://doi.org/10.21747/9789898969217/paraa8

from the Corpus de Produções Escritas de Aprendentes de PL2 (PEAPL2) (Corpus of Written Productions by Learners of Portuguese as a Second Language), from CELGA/ILTEC.

Keywords: PFL, intercultural perceptions, emotion, referenciation, objects of discourse

\section{1 - Introdução}

O presente estudo tem por objetivo dar conta dos primeiros resultados de uma investigação sobre manifestações (discursivas) da perceção e da (re)construção da imagem do Outro e da sua cultura (cultura alvo) por aprendentes de PLE, em contexto de imersão.

A aprendizagem de uma LE é também a "aprendizagem" da cultura (no sentido mais lato) que Ihe está associada. Em contexto de imersão, o desenvolvimento dessas competências culturais (interculturais) apresenta contornos muito particulares, sendo naturalmente expectável uma maior visibilidade desse processo, destacando-se aqui as manifestações discursivas das múltiplas perceções que vão sendo construídas sobre os objetos alvo e sobre o próprio processo subjetivo de integração. Concomitantemente, a imagem prévia do Outro, referenciado diretamente como "coletivo" ou exemplarmente filtrado por experiências de contacto num plano mais local, é, neste contexto, muitas vezes (re)ajustada/(re)construída (explícita ou implicitamente), em função das (novas) experiências vivenciadas.

Entendida como narrativa (mais coletiva ou mais individual), a construção destas perceções deve, assim, ser analisada/observada privilegiadamente nas configurações discursivas-textuais das produções destes sujeitos, em particular nos processos de referenciação e na construção dos respetivos objetos de discurso, enquanto representativos das entidades assim percecionadas e configuradas. É nesse sentido que nos propomos observar a estruturação textual-discursiva, focando os mecanismos enunciativos envolvidos subjacentes a expressões referenciais do tipo "os portugueses" ou "a comida portuguesa", "a vida portuguesa", entre outras.

Enquanto objetos de discurso, a construção e dinâmica destas referências resultará de um conjunto de processos inerentes aos diferentes planos da dinâmica do texto. Neste âmbito, parece-nos relevante convocar, antes de mais, para a discussão o estatuto sintático-semântico que Ihes é atribuído, quer no plano da frase (micro), quer no plano do texto (macro), (i) surgindo em posição ora de sujeito (tópico) ora de objeto 
GIL, Isabel; Loureiro, Ana Paula - "Os portugueses sabem bem desenrascar sem panicar."... Para lá da tarefa: implicar os estudantes na aprendizagem de línguas estrangeiras no ensino superior. Porto: FLUP, 2019, pp. 149-166 DOI: https://doi.org/10.21747/9789898969217/paraa8

de frase, (ii) assumindo papel de agente, paciente, estímulo ou tema, (iii) integrando cadeias referenciais mais ou menos relevantes e extensas, entre outros. Por outro lado, e porque é de perceção subjetiva e afetiva que aqui falamos, importa, a nosso ver, observar, em todo este processo narrativo, o posicionamento e as manifestações do EU subjetivo e os Pontos de Vista.

O trabalho tem por base a análise das produções escritas disponíveis no corpus de Produções Escritas de Aprendentes de PLE, PEAPLE2, do CELGA/ILTEC.

\section{2 - Enquadramento teórico}

\section{1 - A competência intercultural no QECRL}

No conjunto das competências gerais individuais definidas pelo QECRL para o ensino/aprendizagem de uma língua estrangeira, e considerando aqui especificamente a dimensão intercultural destas aprendizagens, parece-nos particularmente relevante 0 papel que, neste processo, assume a competência existencial, definida como "a soma das características individuais, traços de personalidade e atitudes" (QECRL, p. 32). Esta competência existencial é tanto mais importante porquanto "tem uma raiz cultural e é, portanto, uma área sensível para as perceções e relações interculturais [...]" (QECRL, p. 33).

Distinguem-se, neste âmbito, entre outros fatores, tipos de atitudes dos aprendentes, relacionados com o modo como são capazes de se posicionar relativamente (1ํ) às novas experiências e ao Outro, assumindo na interação uma maior ou menor abertura, $\left(2^{\circ}\right)$ à sua zona de conforto etnocêntrica, sendo capazes de uma maior ou menor relativização, reposicionando-se, em última análise, a si próprios também como Outro e $\left(3^{\circ}\right)$ ao capital de construções prévias (disponibilizadas por vozes doxais, estereótipos, por discursos Outros), em relação às quais se observa uma maior ou menor capacidade de revisão e reposicionamento, tornando-se, mais ou menos, capazes de, enquanto mediadores, desmontar e resolver essas visões pré-construídas (QECRL, p. 152). Percorrendo diferentes dimensões, de um plano mais local e pontual a um plano mais global e permanente, a (re)construção destas perceções abrirá caminhos para o desenvolvimento progressivo de uma sólida competência pluricultural e plurilingue. 
GIL, Isabel; Loureiro, Ana Paula - "Os portugueses sabem bem desenrascar sem panicar."... Para lá da tarefa: implicar os estudantes na aprendizagem de línguas estrangeiras no ensino superior.

Porto: FLUP, 2019, pp. 149-166

DOI: https://doi.org/10.21747/9789898969217/paraa8

\section{2 - A emoção na aprendizagem de LE. Objetos de discurso e Ponto de Vista}

Quando falas com um homem numa língua que ele entende, a informação vai para a sua cabeça. Quando falas com ele na sua própria língua, a informação vai para o seu coração. (Nelson Mandela, adapt.)

Partindo do princípio de que as disposições de ordem afetiva se ligam a preferências e a aptidões (Damásio, 1994, 1999), a aquisição de uma língua envolve, num sentido amplo, a modificação de perceções, a construção de distintas representações da realidade, o que levará a um agir sobre ou em função dessa mesma realidade diremos que apre(e)nder uma língua/cultura constitui um processo do qual faz parte a construção de novos ou diferentes pontos de vista. O envolvimento emocional do aprendente reflete um posicionamento de pertença / proximidade relativa à língua / cultura alvos ou, pelo contrário, o afastamento / a recusa do aprendente. Potencialmente geradoras de sim-patia (Charaudeau, 2000), as emoções constituem eixos fundamentais no processo de integração, intercompreensão e interculturalidade.

É inegável o papel da dimensão emocional no discurso e, portanto, também na aprendizagem das línguas. Tal como refere Plantin (2011), um discurso "alexitímico" é um discurso patológico; as emoções, definidas por ora como disposições de ordem psicológica, passional e cognitiva permeiam as interações verbais, são catalisadoras de co-construções discursivas (cf. Plantin (1999, 2011) e Micheli (2008), plasmando-se no discurso com intensidade variável (Kerbrat-Orecchioni, 1980, p. 22).

Se bem que o domínio lexical (em particular no que tange aos adjetivos) seja uma área de análise privilegiada no que concerne às emoções ${ }^{1}$, também a argumentação e a aprendizagem das línguas constituem desde há alguns anos áreas de interesse relativamente ao papel das emoções (Kerbrat-Orecchioni, 2000). Vejam-se, por exemplo, os estudos de Plantin e Micheli, que defendem que as emoções são "argumentáveis", constituindo objetos do discurso e orientando a co-construção de interações verbais: o tipo de eventos, a maior ou menor proximidade espácio-temporal, o caráter agentivo ou passivo dos intervenientes envolvidos num dado evento subjazem ao fio do discurso.

\footnotetext{
${ }^{1}$ Não faremos neste âmbito a distinção entre "emoções" e "sentimentos", antes considerando o lexema "emoção" como termo genérico relativo a disposições de ordem, afetiva e passional, como «les états constitutifs de la vie affective» (Cosnier, 1994, p. 161).
} 
GIL, Isabel; Loureiro, Ana Paula - "Os portugueses sabem bem desenrascar sem panicar."... Para lá da tarefa: implicar os estudantes na aprendizagem de línguas estrangeiras no ensino superior. Porto: FLUP, 2019, pp. 149-166 DOI: https://doi.org/10.21747/9789898969217/paraa8

As dimensões afetivas / de feição emotiva estarão, portanto, naturalmente imbricadas na construção dos objetos do discurso, na manifestação de atitudes subjetivas, avaliativas, pelo que postulamos que em causa estão também não apenas competências de ordem linguística-comunicativa e sócio-cognitiva, mas ainda de ordem emocional. Assim se verifica, no corpus analisado, as avaliações subjetivas e a maior ou menor proximidade dos aprendentes face à língua segunda/estrangeira e aos próprios falantes dessa língua-alvo. A identificação e descrição dos afetos traduzidos na materialidade linguística não devem ser alheios ao ensino-aprendizagem das línguas e culturas estrangeiras - esta é uma componente fundamental no que à didática do ensino do PLE (no caso em apreço) tange.

Assim, a construção de objetos do discurso revela diferentes pontos de vista, diferentes formas de experienciar realidades. Retomando o tópico presente no título deste trabalho ("os portugueses"), adiantaremos que não está em causa um referente de um objeto do mundo real mas um objeto discursivo, resultado de um trabalho de referenciação:

(...) a referenciação é um processo realizado negociadamente no discurso e que resulta na construção de referentes, de tal modo que a expressão referência passa a ter um uso completamente diverso do que se atribui na literatura semântica em geral. Referir não é mais atividade de "etiquetar" um mundo existente e indicialmente designado, mas sim uma atividade discursiva de tal modo que os referentes passam a ser objetos-de-discurso e não realidades independentes. [...] a referenciação é um processo discursivo e (...) os referentes são objetos-de-discurso, não Ihes cabendo um estatuto ontológico apriorístico (Koch \& Marcuschi, 1998).

Apresenta-se-nos o resultado de uma construção discursiva, de um processo de referenciação. Assim se compreende que a propósito do mesmo tema se manifestem distintos pontos de vista e se façam ouvir diferentes vozes.

A referenciação assenta num comentário meta-enunciativo/meta-discursivo por parte dos locutores/enunciadores. Assim, o objeto do discurso é apresentado segundo um ponto de vista (PDV) determinado, pela voz de um enunciador, e orienta o discurso num dado sentido, para um dado posicionamento. As dimensões de natureza apreciativa e emocional permeiam, justamente, a construção de PsDV, tal como as palavras de Rabatel sublinham: 
GIL, Isabel; Loureiro, Ana Paula - "Os portugueses sabem bem desenrascar sem panicar.”... Para lá da tarefa: implicar os estudantes na aprendizagem de línguas estrangeiras no ensino superior. Porto: FLUP, 2019, pp. 149-166 DOI: https://doi.org/10.21747/9789898969217/paraa8

On nommera PDV tout ce qui, dans la référenciation des objets (du discours), révèle, d'un point de vue cognitif, une source énonciative particulière, et dénote, directe ou indirectement, ses jugements sur les référents - d'où l'importance des dimensions axiologiques et affectives du PDV. (Rabatel, 2003, p. 8)

Por outro lado, a designação ou descrição de um objeto ou processo deriva de um processo de negociação com o discurso do Outro e com a alteridade constitutiva do interdiscurso. Daí que Mondada (2002) refira que os objetos do discurso são construídos no e pelo discurso, transformando-se a partir do contexto, revelando uma instabilidade ${ }^{2}$ que lhes é inerente. Em causa estão (re)categorizações discursivas, "uma dimensão intrínseca do discurso e da cognição".

No(s) discurso(s) analisados a partir do corpus plasmam-se estereótipos, outras vozes, o "já-dito" ou o "on-dit". Essas vozes que se fazem assim ouvir trazem para o discurso diferentes perspetivas, tábuas de valores e saberes partilhados em comunidades distintas - assim, não é só o EU o responsável pela enunciação de perspetivas ou de avaliações. De resto, como se sabe, da atividade discursiva é constitutiva a polifonia e o dialogismo (no sentido bakhtiniano). Esta orientação dialógica, basilar, do discurso postulada por Bakhtine e Volochinov faz com que no discurso do EU esteja sempre o OUTRO. Note-se que o dialogismo bakhtiniano radica na intersubjetividade e alteridade nucleares/constitutivas que confirmam a heterogeneidade omnipresente no discurso, através da convocação de vozes várias, "[...] já que todo o discurso convoca outros discursos, para eles remete, com eles dialoga de múltiplas formas" (Fonseca, 1994, p. 81).

Também Brès \& Nowakowska (2007, pp. 113-114) associam o conceito de voz ao dialogismo como princípio constitutivo de qualquer discurso, orientando este para outros discursos, quer no polo da produção, quer no polo da receção.

Adotar-se-á a expressão "point de vue" (doravante PDV) tal como Rabatel (2005) o propõe: o PDV, cuja construção subjaz à distinção entre locutor e enunciador, é definido como modo de referenciação que denota uma perspetiva, individual, coletiva ou doxal, representando o objeto ou entidade na origem desse ponto de vista, i.e., o enunciador que toma a seu cargo a enunciação. Este ponto de vista (PDV) encerra em si avaliações axiológicas, processos cognitivos, tímicos e ideológicos (Rabatel, 2005, p. 96). Note-se

2 Ainda que essa instabilidade possa ser ultrapassada pela categorização na base da prototipicidade e estereotipização. 
GIL, Isabel; Loureiro, Ana Paula - "Os portugueses sabem bem desenrascar sem panicar."... Para lá da tarefa: implicar os estudantes na aprendizagem de línguas estrangeiras no ensino superior. Porto: FLUP, 2019, pp. 149-166 DOI: https://doi.org/10.21747/9789898969217/paraa8

que um mesmo enunciador pode estar na origem de diferentes PsDV (contrariamente ao que se postula na teoria polifónica de Ducrot).

Seguindo as propostas de Rabatel (2003, 2005, 2009), tomamos 'posicionamento' como uma dimensão constitutiva do texto através da qual se faz(em) ouvir a(s) voz(es) do discurso, que assumem um maior ou menor distanciamento face a um conteúdo proposicional, assumindo (ou não) a responsabilidade enunciativa de um PDV. Assim, os mecanismos de referenciação articulam-se necessariamente à fonte enunciativa.

Diferentes vozes são postas em cena pelo Locutor/Enunciador ${ }^{3}$ (Rabatel, 2005), sendo que este nem sempre se identifica com as vozes que introduz no discurso, abrindo desse modo o caminho à contestação ou desacordo, eventualmente reformulando o discurso. L1/E1 referir-se-á a um locutor-enunciador primeiro que poderá imputar a responsabilidade enunciativa a um 12/e2, enunciador secundário; embora L1/E1 possa convocar I2/e2, poderá não assumir a responsabilidade pelo PDV deste - daí a designação de "segundo" (Ainda no que tange à questão da responsabilidade enunciativa e do posicionamento de $L$ face à enunciação, Rabatel refere-se à "prise en compte", caso em que L não assume a responsabilidade de um PDV, antes a atribui a um $12 / \mathrm{e} 2$, dando lugar a momentos de desacordo ou de concessão.)

\section{3 - Dados empíricos}

Propomo-nos, neste estudo, analisar ocorrências, nos textos de aprendentes de PLE, de expressões referenciais que remetam para entidades do universo do Outro, privilegiadamente sintagmas que representem o Outro enquanto coletivo, "os portugueses". Sendo que estas expressões referenciais, vistas como objetos de discurso, são simultaneamente um produto e um elemento criador dos seus con/cotextos, é nosso propósito identificar alguns aspetos semântico-sintáticos e pragmáticos deste seu processo construtivo, quer ao nível frásico, quer ao nível da organização discursivo-textual. Para tal, selecionámos algumas ocorrências do referido corpus, que, de forma mais exemplar, poderão evidenciar a construção identitária do Eu e do Outro, refletida nas escolhas lexicais, nas estruturas sintático-semânticas e, numa dimensão mais global, na composição e organização textuais.

\footnotetext{
${ }^{3}$ Que passamos a designar por E1/L1, aquele que se responsabiliza pelo PDV que se sobrepõe a outros.
} 
GIL, Isabel; Loureiro, Ana Paula - "Os portugueses sabem bem desenrascar sem panicar.”... Para lá da tarefa: implicar os estudantes na aprendizagem de línguas estrangeiras no ensino superior.

Porto: FLUP, 2019, pp. 149-166 DOI: https://doi.org/10.21747/9789898969217/paraa8

\section{1 - Metodologia}

Para este estudo servimo-nos dos dados disponíveis no Corpus PEAPL2, constituído por textos escritos produzidos por aprendentes de PLE que frequentam os cursos, de diferentes tipologias, de Português para Estrangeiros da FLUC. Este acervo reúne produções escritas de aprendentes de diferentes nacionalidades e LM, com idades compreendidas entre os 16 e os 68 anos, de níveis $A 1$ a $C 1$.

Procedemos ao levantamento de todas as ocorrências do lexema português, nome ou adjetivo (nas diferentes formas de género e número), em sintagmas com valor referencial definido e genérico. Dos resultados obtidos, considerámos as seguintes estruturas, num total de 121 ocorrências:

(i) sintagmas nominais do tipo "(todos) os portugueses", regularmente ocorrendo como forma de referenciar o Outro como uma comunidade, em sentido amplo (31 ocorrências);

(ii) sintagmas remetendo para aspetos vários da vida e cultura portuguesas " $D e t$ + N + Adj "português"” (ex.: "a vida portuguesa", "a comida portuguesa", etc.) (75 ocorrências);

(iii) sintagma nominal "as pessoas", em contextos em que claramente se reconhece uma referência a "os portugueses" (15 ocorrências).

Estas estruturas foram depois classificadas e organizadas em função de um conjunto de categorias, de acordo com o que nos propusemos analisar. Assim, antes de mais, classificámos as expressões tendo em consideração o estatuto sintático-semântico que Ihes é atribuído na frase e no texto, nomeadamente,

i. a sua função sintática na frase (sujeito/tópico, complemento ou outro);

ii. o nível frásico em que ocorrem (frase principal ou encaixada);

iii. os tipos de predicação envolvidos (tipos de situações);

iv. a construção do texto: eixos semântico-pragmáticos dominantes na construção discursiva/textual da relação entre o Eu e o Outro.

Por outro lado, e do ponto de vista da sua dimensão enunciativa e pragmática destacando-se as dimensões emotivas/subjetivas imbricadas na construção de PsDV -, estas estruturas foram analisadas de acordo com os seguintes tópicos:

v. tipologia de objetos do discurso, isto é, os tipos de vivências convocados nos textos e a sua dimensão (mais locais ou mais gerais); 
GIL, Isabel; Loureiro, Ana Paula - "Os portugueses sabem bem desenrascar sem panicar.”... Para lá da tarefa: implicar os estudantes na aprendizagem de línguas estrangeiras no ensino superior. Porto: FLUP, 2019, pp. 149-166 DOI: https://doi.org/10.21747/9789898969217/paraa8

vi. eixo avaliativo/afetivo - seleção lexical e manifestações linguísticas de cariz emocional;

vii. voz do Eu e voz do Outro: PDV, posicionamento e relativização.

Nos parágrafos que se seguem, daremos conta de alguns dados e reflexões acerca destas questões. Como referimos, concentraremos a nossa atenção sobretudo nas ocorrências do sintagma "os portugueses".

\section{2 - Dados e resultados. Análise}

Do ponto de vista do estatuto que adquire no domínio da Frase, o SN "os portugueses" (31 ocorrências) ocorre maioritariamente como sujeito (22 casos), correspondendo os restantes casos sobretudo a posições dentro de um complemento do verbo (ora como núcleo ora como complemento do núcleo nominal) (9). Enquanto sujeito combina tipicamente com verbos ora do domínio do "ser" e do "saber" (8), ora do domínio dos gostos e hábitos (8). As descrições enquadram-se tipicamente no plano temporal do presente (atemporal ou habitual); pontualmente podem remeter também para aspetos do passado. Relativamente ao nível frásico, estes sintagmas ocorrem tanto ao nível superior de frase (13 ocorrências), como ao nível encaixado de oração subordinada (18 casos). Sejam os seguintes exemplos:

(1) Os portugueses, ao contrário, sabem bem desenrascar sem panicar e as, os espectáculos ficam mais divertidos. (Alemão, B1)

(2) Se me sinto estressada, eu vou às cafés para relajar e falar com os portugueses lá. (Inglês, B1)

(3) Estou sempre a pensar como é que os portugueses conseguem fazer um estilo tão maravilhoso! (Chinês, B1)

(4) A primeira que fiquei surpreendida quando comecei a morar em Portugal como os portugueses beberem. (Japonês, B1)

(5) Eu gosto da cultura portuguesa porque em geral, os portugueses têm muito mais tempo do que os alemães e a vida passa menos depressa. (Alemão, B1)

$\mathrm{Na}$ tabela que se segue, resume-se a distribuição das ocorrências tratadas (do SN "os portugueses", mas também de outros sintagmas que fizeram parte da recolha global) pelas categorias sintático-semânticas definidas, tendo em conta os dados sistematizados até ao momento: 
GIL, Isabel; Loureiro, Ana Paula - "Os portugueses sabem bem desenrascar sem panicar."... Para lá da tarefa: implicar os estudantes na aprendizagem de línguas estrangeiras no ensino superior.

Porto: FLUP, 2019, pp. 149-166 DOI: https://doi.org/10.21747/9789898969217/paraa8

\begin{tabular}{|c|c|c|c|c|c|c|c|c|c|}
\hline \multirow[t]{2}{*}{ SN } & \multirow[t]{2}{*}{ Total } & \multicolumn{3}{|c|}{ Estatuto sintático } & \multicolumn{2}{|c|}{ Nível frásico } & \multirow[b]{2}{*}{ Outros } & \multirow{2}{*}{$\begin{array}{l}\text { Predicado } \\
\text { SER/saber }\end{array}$} & \multirow[b]{2}{*}{$\begin{array}{l}\text { Gostos } \\
\text { /hábitos } \\
\text { ("fazer") }\end{array}$} \\
\hline & & $\begin{array}{l}\text { Sujei- } \\
\text { to }\end{array}$ & $\begin{array}{l}\text { Comple- } \\
\text { mento }\end{array}$ & Outro & $\mathbf{F}$ & $\begin{array}{l}\text { Subordi- } \\
\text { nada }\end{array}$ & & & \\
\hline $\begin{array}{l}\text { "os } \\
\text { portugueses" }\end{array}$ & 31 & 22 & 9 & & 13 & 18 & & 8 & 8 \\
\hline "as pessoas" & 15 & 12 & 2 & 1 & 7 & 7 & 1 & 9 & 3 \\
\hline $\begin{array}{l}\text { "Det N + Adj } \\
\text { (português")" }\end{array}$ & 74 & 9 & 41 & 24 & 52 & 17 & 5 & & \\
\hline
\end{tabular}

Tabela 1. Distribuição das ocorrências analisadas

Um dos aspetos que mais se salienta nas ocorrências aqui analisadas diz respeito às construções em que os objetos de discurso se constituem como sujeito de predicações com o verbo ser. Nestes contextos, é interessante observar as áreas de adjetivação mais salientes e o polo em que situam a apreciação, porquanto estas manifestações podem ser indicadoras de uma maior ou menor proximidade ou afastamento do Eu em relação ao Outro e da eventual construção de sentimentos de pertença, de intensidade variável, a uma nova comunidade. Assim, os adjetivos identificados no corpus em análise configuram apreciações globalmente positivas e remetem sobretudo para atitudes interpessoais. (os portugueses são... abertos/fechados, relaxados, simpáticos, divertidos, disponíveis, alegres).

(6) Oxalá um dia puderes passar umas férias aqui, eu acho que o pais ${ }^{4}$ em geral é ótimo e os portugueses são, na majoria, muito relaxachos e abertos. (Inglês, B1)

(7) O Portugal é muito lindo e os portugueses são simpaticos, divertidos, disponívéis. (Italiano, B1)

(8) A comida aquí é muito boa, mais o menos como a nossa e os portuguêses são simpáticos más é um povo um pouco fechado em elação aos italianos ou espanholes. (Italiano, B2)

(9) Em comparação com o nosso país, as pessoas aqui são mais hospitaleiros e grande apreciadores da vida, isto é, eles sabem fazer tudo tranquilamente e à vontade, raramente mal-dispostos. (Chinês, C1)

Em função do contexto espacial mais marcante em que ocorrem as perceções (mais

${ }^{4}$ Os segmentos retirados do corpus serão transcritos tal e qual se apresentam no original. 
GIL, Isabel; Loureiro, Ana Paula - "Os portugueses sabem bem desenrascar sem panicar."... Para lá da tarefa: implicar os estudantes na aprendizagem de línguas estrangeiras no ensino superior. Porto: FLUP, 2019, pp. 149-166 DOI: https://doi.org/10.21747/9789898969217/paraa8

local ou mais global), poderá evidenciar-se, neste tipo de enunciados, com maior ou menor clareza, o surgimento de uma outra dimensão subjetiva: a emoção. Efetivamente, os textos, além de serem percorridos por uma dimensão axiológica apresentam também uma dimensão de emoção: os objetos sobre os quais recai a avaliação estão na origem de sentimentos/emoções. A avaliação do objeto do discurso permite reconstruir essa carga emotiva, já que o referido objeto se apresenta como um agente causador (estímulo) de estados psicológicos vários (Plantin, 2011; Iva \& Novakova, 2014). A expressão destas emoções está relacionada com avaliações de caráter axiológico, de preferências, de manifestações subjetivas face à cultura-alvo ou de experienciação de estados psicológicos/afetivos induzidos por vivências num contexto de imersão na cultura-alvo. A expressão linguística da emoção encontra-se no uso de lexemas pertencentes sobretudo à classe dos verbos e dos adjetivos.

Os exemplos (6) e (7) contêm uma avaliação subjetiva manifestada linguisticamente por adjetivos que se situam num polo positivo. "Relaxados" e "abertos" surgem regularmente como qualidades valorizadas pelos falantes de vários países; por inferência e dados os conhecimentos enciclopédicos, os saberes partilhados, dir-se-á que L1/E1 é experienciador de estados psicológicos/afetivos situados na zona das emoções positivas (Plantin, 2011, pp. 122-123). As qualidades atribuídas aos portugueses pressupõem experiências vividas (por exemplo, dificuldades sentidas pelo falante estrangeiro ultrapassadas com a disponibilidade e simpatia de um português), que funcionam como estímulo para uma apreciação positiva ( $X$ simpatiza com $Y$ / X está disponível para Y). A experienciação desses estados psicológicos pode variar de intensidade: no exemplo (6), infere-se que o Loc. é experienciador de um estado de ordem psicológica/afetiva de maior intensidade, dada a expressão do desejo (por derivação ilocutória, uma sugestão ou mesmo um convite) de que o interlocutor venha também a Portugal conhecer o país e os portugueses.

Outros exemplos, como os de (2) e (5), supra, manifestam também estados de índole emocional: em (2) L1/E1 explicita ou diz (Micheli, 2008) sentimentos/estados psicológicos situados num polo negativo, como o "stress", que funcionam como estímulo para procurar o contacto com a cultura-alvo e assim experienciar emoções/sentimentos assimilados como positivos. Também a avaliação subjetiva contida no exemplo (3) manifesta um estado emocional situado no eixo do positivo: a superlativização do adjetivo, aliada à manifestação de um estado permanente que se infere ser de admiração e de valorização, traduzem linguisticamente a emotividade induzida pelo contacto com os portugueses. Estes são, assim, referenciados como um povo que se 
GIL, Isabel; Loureiro, Ana Paula - "Os portugueses sabem bem desenrascar sem panicar."... Para lá da tarefa: implicar os estudantes na aprendizagem de línguas estrangeiras no ensino superior. Porto: FLUP, 2019, pp. 149-166 DOI: https://doi.org/10.21747/9789898969217/paraa8

admira e que cativa. O exemplo (5) é particularmente interessante em função da subjetividade envolvida na definição do tempo: este é avaliado como "mais longo" (idêntica avaliação surge noutros exemplos do corpus) e a vida é também mais "lenta", por comparação com a sua cultura nativa. Anunciada pelo emprego do verbo gostar, constrói-se uma avaliação situada num eixo semântico de polaridade positiva; a apreciação subjetiva da temporalidade constitui o momento inicial de uma valoração afetiva.

No exemplo (9), referencia-se o tempo de forma idêntica, levando igualmente ao mesmo tipo de valoração. As qualidades subjacentes à valorização da cultura portuguesa são indutoras de um movimento de aproximação ou assimilação. Infere-se que os Locs./Enuncs. são experienciadores de estados opostos ao "stress" referido noutro exemplo (2).

Para além do verbo gostar, vazado em estruturas do tipo $\mathrm{X}$ gostar de $\mathrm{Y}$, ou do verbo apreciar, surgem outros verbos, igualmente associados a emoções positivas, tal como o verbo impressionar, do exemplo (10):

(10) A Queima das Fitas é impressionei-me, mas não é verdade que os portugueses bebem o muito cerveja do mundo. (Alemão, A1)

$\mathrm{Na}$ tabela que se segue, resumem-se alguns dados da distribuição do léxico pelos eixos de avaliação, positiva ou negativa:

\begin{tabular}{|l|l|l|}
\hline & Eixo das avaliações positivas & $\begin{array}{l}\text { Eixo das avaliações } \\
\text { negativas }\end{array}$ \\
\hline Verbos & gostar [muito], impressionar(-se), adorar & \\
\hline Adjetivos & $\begin{array}{l}\text { disponível, amigável, relaxado, tranquilo, "estressado", fechado } \\
\text { apreciador, bom/boa, hospitaleiro, } \\
\text { simpático, maravilhoso, aberto }\end{array}$ & \\
\hline Nomes & Tranquilidade & \\
\hline
\end{tabular}

Tabela 2. Distribuição do léxico pelos eixos de avaliação

Um outro aspeto que se evidencia nestas produções relaciona-se com as perceções e avaliações/emoções acerca dos (e a partir dos) comportamentos e atitudes do Outro (da cultura alvo). Voltando ao exemplo que dá título a este estudo (1), observamos que o Loc. se coloca no centro da apreciação, apresentando-se como alguém que se diverte 
GIL, Isabel; Loureiro, Ana Paula - "Os portugueses sabem bem desenrascar sem panicar."... Para lá da tarefa: implicar os estudantes na aprendizagem de línguas estrangeiras no ensino superior. Porto: FLUP, 2019, pp. 149-166 DOI: https://doi.org/10.21747/9789898969217/paraa8

e que experiencia sentimentos de calma ou descontração pelo contacto com o povo e a cultura alvos da sua aprendizagem. Este L1/E1 procede à construção do objeto de discurso a partir de e2, uma voz coletiva ou doxa vigente na cultura alvo, que associa uma característica tomada como inerente aos portugueses, o "desenrascanço", antes de mais, e a calma perante o inesperado, a partir do neologismo "panicar". Relativamente ao Outro, L1/E1, assimila a sua voz à de e2, partilhando, então, E1 e e2 o mesmo PDV. Isto também é aprendizagem - a aprendizagem do próprio ponto de vista dos nativos sobre si próprios. O "saber bem" orienta o alocutário para uma conclusão $(C)$ que se situa num eixo avaliativo positivo: aos portugueses são atribuídas qualidades a ser apreciadas e indutoras de estados psicológicos/afetivos positivos, já que tais qualidades criam diversão e "espetáculo". O léxico utilizado nesta avaliação parece indiciar, de uma perspetiva cognitiva, que subjacente à aprendizagem da língua e da cultura está a experienciação de emoções situadas num polo positivo (na maioria dos casos).

Para finalizar, apresentam-se os exemplos (11) e (12):

(11) Ainda que tente acostumar-me à vida portuguesa, as vezes tenho muitas dificuldades a esperar com paciência e não me preocupar com o tempo. (Alemão, B1)

(12) Portanto, o mais importante cá é se adaptar à cultura portuguesa que significa que tem de tomar café ou chá toda hora. (Alemão, B1)

O Loc./Enunc. de cada um destes textos assume um aspeto relevante na aprendizagem de uma língua e cultura: a assimilação de hábitos rotineiros e de tentar experienciar vivências tipificantes da alteridade. As avaliações axiológicas e a reconstrução do objeto do discurso "os portugueses" ligam-se, como se disse, a dimensões emotivas, polarizadas em torno de «savoirs de croyances», nas palavras de Charaudeau (2000). As dimensões de cariz emotivo são, por vezes, ditas ou, noutros casos, recuperadas a partir da avaliação da língua e cultura estrangeiras.

Um outro plano de análise procura observar nestas construções discursivas evidências de movimentos de revisão e reposicionamento em relação aos préconstruídos disponíveis na cultura de partida, resultado de tábuas de valores e saberes compartilhados nessa mesma comunidade. Efetivamente, é por via desta mesma dimensão avaliativa/emotiva, que temos vindo a referir, que emergem sinais de uma reanálise das ideias feitas acerca do Outro, muito frequentemente tomando como 
GIL, Isabel; Loureiro, Ana Paula - "Os portugueses sabem bem desenrascar sem panicar."... Para lá da tarefa: implicar os estudantes na aprendizagem de línguas estrangeiras no ensino superior. Porto: FLUP, 2019, pp. 149-166 DOI: https://doi.org/10.21747/9789898969217/paraa8

paradigma (necessariamente subjetivo) comparações com culturas tomadas genericamente como próximas da cultura alvo.

Importa ainda, nestes contextos, referir que as vozes convocadas nos discursos estão frequentemente ao serviço destes atos discursivos, argumentativos ou de reformulação, modalizando o discurso do sujeito enunciador (e também o discurso do Outro); tal implica, muitas vezes, a reformulação de discursos anteriores e o reposicionamento do Loc. face aos conteúdos previamente veiculados na sua comunidade de origem.

Considerem-se os seguintes exemplos, ilustrativos destes movimentos:

(13) Antes de chegar a Portugal eu achei que tudos os portueses foram semelhantes aos espanhóis mas rapidamente di conta que não era certo (Inglês, B1)

(14) os portugueses são mais abertos do que achava, e foi uma sorpresa bem agradável. (Italiano, B1)

(15) A comida aquí é muito boa, mais o menos como a nossa e os portuguêses são simpáticos más é um povo um pouco fechado em relação aos italianos ou espanholes. (Italiano, B2)

(16) Acho que a única diferença é que os ingleses vão aos países estrangeiros e embebam-se naqueles países e os portugueses costumam ficar em Portugal. (Inglês, B1)

(17) Além disso, pessoalmente creio que os portugueses, em geral, bebem tanto como os ingleses embora os ingleses sejam mais conhecidos por serem bêbedos. (Inglês, B1)

(18) Eu sei que tu achaste sempre que os portugueses sao quase iguais como espanhois, mas não por nada. (Alemão, B1)

(19) Mesmo havendo diferenças entre a cultura portuguesa e a cultura inglesa, não acho que as pessoas sejam tão diferentes. (Inglês, B1)

A expressão adverbial temporal no início de (13) marca a transição entre dois momentos relacionados com um processo cognitivo que se inicia depois da chegada a Portugal. Esse processo cognitivo desencadeia-se como uma reconstrução do objeto do discurso "os portugueses". Evocando o seu próprio PDV num momento anterior, o Loc. convoca-se como um enunciador (e1) - de um enunciador segundo, conforme postulado por Rabatel (2005), por oposição à voz de um enunciador primeiro E1 — cuja 
GIL, Isabel; Loureiro, Ana Paula - "Os portugueses sabem bem desenrascar sem panicar."... Para lá da tarefa: implicar os estudantes na aprendizagem de línguas estrangeiras no ensino superior. Porto: FLUP, 2019, pp. 149-166 DOI: https://doi.org/10.21747/9789898969217/paraa8

voz desvaloriza no momento da enunciação. Essa voz de E1 arrasta consigo uma outra voz - uma voz coletiva ou uma doxa - a de um e2. Segundo essa voz, portugueses e espanhóis seriam povos parecidos, na base de estereótipos difundidos no seu país de origem. Note-se que anteriormente existiria sincretismo entre e1 e e2, já que o L1 não tinha conhecimento direto da língua e cultura portuguesas. Este Loc./Enunc., cujo PDV se sobrepõe no momento presente $(E 1)$, marca o distanciamento face à sua perspetiva anterior; o conector "mas" re-orienta precisamente o Alocutário para essa mudança de PDV, refutando e retificando o PDV anterior. Dá-se, pois, um reposicionamento do Loc. face ao objeto. A conclusão a que este Loc/Enunc. chega é a de que os portugueses são um povo com características distintas das dos espanhóis.

Em (14), a reconstrução do objeto faz-se a partir da comparação (explicitada sintaticamente) entre o PDV de um Eu anterior e o de um Eu situado num momento presente. Tal como no exemplo anterior, E1 sobrepõe-se a e $1^{5}$ e, possivelmente, a e2. A diferença que se opera cognitivamente é assinalada por este Loc./Enunc. como uma "surpresa", valorizada positivamente (veja-se o semantismo do adjetivo "agradável") — a sua avaliação indicia um envolvimento de contornos afetivos/emocionais concorrente com o processo de aprendizagem. Neste caso, a asserção de que os portugueses são "abertos" pressupõe uma outra qualidade previamente atribuída e valorizada negativamente (um povo "fechado").

Idêntico mecanismo de reposicionamento, envolvendo uma comparação, se verifica em (15), embora a conclusão no que tange a características psicológicas dos portugueses se situe num polo inverso: os portugueses serão "fechados". Contraria-se uma voz coletiva que agruparia os portugueses no conjunto de "povos mediterrânicos" (expressão a ser tomada neste contexto como um hiperónimo designando os povos do sul da Europa) conhecidos por serem "abertos". Note-se que este reposicionamento apela a um cálculo inferencial por parte de um Aloc., na base do qual os portugueses estariam inseridos num grupo mais amplo. O Eu situado no momento da enunciação contraria ou não assimila essa voz coletiva, pressupondo-se a prévia assimilação da mesma.

Também em (16) o Loc. refere um reposicionamento face ao objeto: é a constatação de um hábito dos portugueses que leva o falante a reposicionar-se face ao seu conhecimento da cultura portuguesa. O Loc. introduz na enunciação um PDV prévio, pelo qual já não se responsabilizará, manifestando assim um afastamento mais ou menos gradual em relação a constructos prévios.

\footnotetext{
${ }^{5}$ Referimos por e1 a origem enunciativa do PDV anterior, agora reformulado, de E1.
} 
GIL, Isabel; Loureiro, Ana Paula - "Os portugueses sabem bem desenrascar sem panicar."... Para lá da tarefa: implicar os estudantes na aprendizagem de línguas estrangeiras no ensino superior. Porto: FLUP, 2019, pp. 149-166 DOI: https://doi.org/10.21747/9789898969217/paraa8

A convocação de uma voz coletiva como validação de um PDV sustentado num momento anterior é, portanto, recorrente nos exemplos que constam do corpus, como se pode verificar no exemplo (17). Neste enunciado, o segmento introduzido pelo conector concessivo convoca essa voz coletiva, reconhecível na estrutura passiva "ser conhecido por (+F)"; em contraste com o sujeito indeterminado (sintaticamente) da voz coletiva, surge a voz do Eu destacada por um advérbio orientado para o falante ("pessoalmente"), em dissonância com uma voz coletiva de um discurso anterior, o que se traduz numa nova perspetiva face ao povo/cultura-alvo. Como já se terá visto, este reposicionamento do Eu face ao Outro faz-se tomando por referência a cultura nativa, como seria, aliás, expectável. Assim, o Loc./Enunc. toma características que assume como tipificantes da sua cultura para com base nelas comparar a sua cultura / o seu povo com a cultura alvo da sua aprendizagem. Veja-se novamente o exemplo (16), que carreia igualmente um PDV baseado em características assumidas como típicas da cultura do Loc.

Como vemos, a opinião do Outro, quer se trate de um Tu explícito quer se trate de uma voz coletiva, é convocada numa base regular nos discursos dos falantes. A figura de um Tu é usada e explicitada nalguns enunciados, como é o caso de (18). Neste enunciado, L1/E1 interpela diretamente um Tu, e2, cuja voz carreia um PDV que o L1/E1 contraria. O conector "mas" assinala uma negação polémica, reorientando-se argumentativamente o discurso para uma conclusão inversa $(-C)$, que se pode glosar como "Contrariamente ao que tu dizes, os portugueses não são parecidos com os espanhóis." O enunciador citado (e2) e o seu PDV estão na origem de posturas enunciativas divergentes. Semântico-pragmaticamente, é do interesse do Loc./E1 convocar o Outro, e2, pois a discordância que manifesta face ao PDV deste serve os seus objetivos - com base numa experiência de imersão numa cultura alheia, validar um PDV antagónico a um PDV veiculado num momento anterior.

O exemplo (19), tal como já visto anteriormente, convoca uma voz doxal, face à qual, de novo, E asserta o seu PDV (resultante do contexto de imersão em que decorre o seu processo de aprendizagem). O contraste entre dois PDV, o de L1/E1 e e2, é patente através do uso de uma estrutura concessiva, sendo que o conteúdo proposicional do segmento introduzido por "mesmo" carreia o PDV do qual L1/E1 discorda. Depois de um momento de aparente convergência (parcial) entre os dois enunciadores, é L1/E1 que se sobrepõe, impondo um PDV distinto. 
GIL, Isabel; Loureiro, Ana Paula - "Os portugueses sabem bem desenrascar sem panicar.”... Para lá da tarefa: implicar os estudantes na aprendizagem de línguas estrangeiras no ensino superior.

Porto: FLUP, 2019, pp. 149-166 DOI: https://doi.org/10.21747/9789898969217/paraa8

\section{4 - Conclusões}

O contexto de imersão destes aprendentes propicia um confronto com uma língua/cultura alvo que passa indubitavelmente por uma avaliação quer da cultura de origem, quer da 'nova' cultura. Essa avaliação surge marcada por subjetivemas, dimensões de caráter emotivo/avaliativo que há que considerar, dado constituírem elementos basilares num movimento de aproximação ou de afastamento relativamente à cultura-alvo.

A avaliação mencionada é, necessariamente, uma re-avaliação: a natureza interdiscursiva, polifónica, dialógica da atividade comunicativa convoca para os discursos o «já-dito», os pré-construídos, de forma mais ou menos estereotipada, o que significa que o primeiro olhar sobre o Outro, sobre a alteridade, nunca é um olhar "neutro", destituído de saberes prévios. Assim, no plano enunciativo, convocam-se as vozes de outros enunciadores (e2, e3, etc.) às quais se sobrepõe a voz de $E 1$ (L1/E1) que se reposiciona face a saberes prévios, veiculados na comunidade de origem. A origem destes saberes prévios é, por vezes, explicitamente atribuída a um Tu (cf. exemplo (18)).

Por outro lado, essa mesma re-avaliação carreia, não raro, um novo olhar sobre a cultura de origem: na base dos processos avaliativos assume particular relevo o recurso a comparações - de forma explícita (X SER como Y) ou de forma mais implícita, através de construções de tipo concessivo. O reposicionamento do aprendente é marcado pelo contraste temporal entre um ANTES e um DEPOIS (note-se a prevalência do PPI e de expressões adverbiais como "antes").

A referenciação do OUTRO faz-se não só pelo uso de expressões como "os portugueses", como também por meio de expressões que denotam áreas manifestamente com mais impacto na experiência de imersão: a gastronomia, a vida estudantil, o convívio com vizinhos, etc.

\section{Referências bibliográficas}

Brès, J., \& Nowakowska, A. (2007). Voix, points de vue... ou comment pêcher le dialogisme à la métaphore. Cahiers de Praxématique, 49, 103-132.

Charaudeau, P. (2000). La pathémisation à la télévision comme stratégie d'authenticité. In Plantin, C.; Doury, M., \& Traverso, V., Les émotions dans les interactions. Lyon: P.U.L., pp. 125-155.

Cosnier, J. (1994). Psychologie des émotions et des sentiments. Paris: Retz. 
GIL, Isabel; Loureiro, Ana Paula - "Os portugueses sabem bem desenrascar sem panicar.”... Para lá da tarefa: implicar os estudantes na aprendizagem de línguas estrangeiras no ensino superior. Porto: FLUP, 2019, pp. 149-166 DOI: https://doi.org/10.21747/9789898969217/paraa8

Fonseca, J. (1994). Pragmática Linguística. Introdução, Teoria e Descrição do Português. Porto: Porto Editora.

Kerbrat-Orecchioni, C. (1980). L'énonciation. De la subjectivité dans le langage. Paris: Armand Colin.

Koch, I. \& Marcuschi, L. A. (1998). Processos de referenciação na produção discursiva. D.E.L.T.A. Documentação de Estudos em Lingüística Teórica e Aplicada, v. 14. Disponível em http://www.scielo.br/scielo.php?script=sci arttext\&pid=S0102-

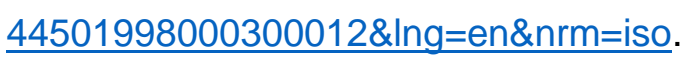

Micheli, R. (2008). L'analyse argumentative en diachronie: le pathos dans les débats parlementaires sur l'abolition de la peine de mort. Argumentation et Analyse du Discours, 1. Disponível em http://journals.openedition.org/aad/482.

Novakova, I. \& Sorba, J.(2014). L'évaluation à travers les émotions : le cas d'estime et de déception. Langue Française, 184, 75-91.

Novakova, I. \& Tutin, A. (Dir.). (2009). Le lexique des émotions. Grenoble: Université Stendhal.

Plantin, C. (1999). La interacción argumentativa. Escritos, 17/18, 23-49.

Plantin, C. (2011). Les bonnes raisons des émotions. Principes et méthode pour l'étude du discours émotionné. Bern: Peter Lang.

Quadro Europeu Comum de Referência para as Línguas. Disponível em http://area.dge.mec.pt/gramatica/Quadro_Europeu_total.pdf.

Rabatel, A. (2003). Le problème du point de vue dans le texte de théâtre. Pratiques, 7-33. Disponível em https://halshs.archives-ouvertes.fr/halshs-00433139.

Rabatel, A. (2005). La part de l'énonciateur dans la construction interactionnelle des points de vue. Marges Linguistiques. M.L.M.S. Publisher, 9, pp.115-136. 